M. Batak*

\title{
REZULTATI ISTRAŽIVANJA STAVOVA I POTREBA PROFESORA STRUČNIH PREDMETA I VODITELJA PRAKTIČNE NASTAVE U SREDNJIM STRUKOVNIM ŠKOLAMA
} UDK 373.546:371.12]:331.45 PRIMLJENO: 27.9 .2018 . PRIHVAĆENO: 12.10 .2018

\begin{abstract}
SAŽETAK: U radu su prikazani rezultati istraživanja stavova i potreba profesora stručnih predmeta $i$ voditelja praktične nastave u srednjim strukovnim školama s težištem na tematsko područje zaštite na radu. Rezultati provedenog istraživanja ukazuju na raznolikost profila osoba (dob, spol i radno iskustvo u podučavanju) koje sudjeluju u nastavnom procesu, posebice kada je riječ o njihovom radnom iskustvu u realnom sektoru. Nadalje, rezultati ukazuju na poteškoće s kojima se nastavnici susreću u svojem radu. Zaključci istraživanja ukazuju na nužnost poduzimanja mjera kojima bi se olakšao transfer znanja te potaknuo razvoj pozitivnih stavova o zaštiti na radu kod učenika.
\end{abstract}

Ključne riječi: profesori stručnih predmeta, voditelji praktične nastave, praktična nastava, srednje strukovne škole, zaštita na radu

\section{UVOD}

"Primjena mjera i informiranost učenika srednjih strukovnih škola o zaštiti na radu" projekt je koji je Hrvatski zavod za zaštitu zdravlja i sigurnost na radu provodio u razdoblju od 2014. do 2017. godine, a s ciljem istraživanja informiranosti učenika o zaštiti na radu te poticanja budućih mladih radnika na promišljanje o važnosti sigurnosti i zaštite zdravlja na radu te samim time i utjecaja na razvoj njihove svijesti o ovom pitanju. Projektom je bilo obuhvaćeno 85 srednjih strukovnih škola i 3624 učenika, a na temelju razgovora s nastavnicima koji sudjeluju u obrazovnom procesu prenoseći znanje iz zaštite na radu, zaključeno je kako postoji potreba dodatnog istraživanja njihovih

*Marija Batak, dipl. ing. sig., (mbatak@hzzzsr.hr), Hrvatski zavod za zaštitu zdravlja i sigurnost na radu, R. Cimermana 64a, 10000 Zagreb. potreba i poteškoća s kojima se u radu susreću. U srednjim strukovnim školama učenike mogu poučavati nastavnici strukovno-teoretske nastave, stručni učitelji, odnosno nastavnici praktične nastave, suradnici u praktičnoj nastavi i/ili nastavnici strukovno-teorijske nastave, a za potrebe ovog rada za sve navedene profile koristit će se pojam nastavnik. On-line istraživanje stavova, iskustava i potreba nastavnika koji educiraju učenike o zaštiti na radu u srednjim strukovnim školama ${ }^{1}$ provedeno je tijekom prosinca 2016. i siječnja 2017. godine. Istraživanjem, u kojem je sudjelovalo 152 nastavnika, željeli su se utvrditi načini i metode podučavanja zaštite na radu, problemi s kojima se nastavnici suočavaju te prijedlozi za unapređivanje obrazovnog procesa.

${ }^{1}$ Krišto, I., Batak, M., Paskaš Dlugoš, S.: Creating a safety culture teaching and learning OSH in secondary vocational schools in Croatia, Book of Abstracts, 56, ICOH SCETOH Symposium, Zagreb, 26. - 28. 10. 2017. 


\section{REZULTATI ISTRAŽIVANJA}

Upitnik sadrži 13 pitanja podijeljenih u 3 cjeline kojima su prikupljani podaci o ispitanicima, načinima pripreme za nastavu i metodama podučavanja koje nastavnici koriste kako bi učenike naučili osnovama zaštite na radu te o izvođenju radnih zadataka na način kojim neće ugroziti svoje zdravlje i sigurnost. Pitanjima iz anketnog upitnika istraživano je iskustvo nastavnika u realnom sektoru kao i načini na koji su stekli znanja iz zaštite na radu. Od ispitanika se tražilo da vrednuju dostatnost propisanog sadržaja iz zaštite na radu, propisanog fonda sati te dostupnih materijala za svladavanje osnovnih znanja iz zaštite na radu, kao i zainteresiranost učenika za zaštitu na radu te prepoznavanje važnosti zaštite na radu od škole u kojoj su zaposleni. Ispitanicima je omogućeno da navedu najčešće poteškoće s kojima se susreću prenoseći znanja iz zaštite na radu, daju prijedloge za svladavanje navedenih poteškoća i istaknu teme (pitanja) bitne za unapređivanje ovog područja koje nisu obuhvaćene konkretnim upitnikom.

Od ukupnog broja ispitanika ( $\mathrm{N}=152)$, njih 57 $(37,50 \%)$ nalazi se u dobnoj skupini od 46 do 55 godina i ovo je ujedno najbrojnija dobna skupina u ovom istraživanju (slika 1).

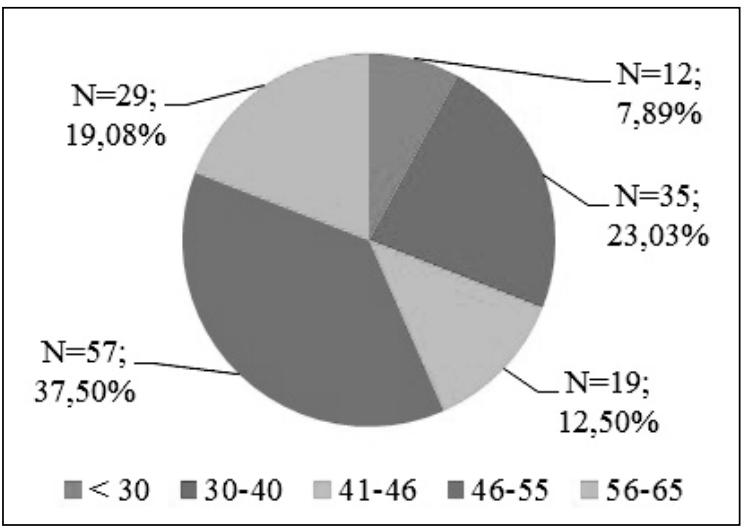

Slika 1. Dob ispitanika

Figure 1. Age of respodents

Od ukupnog broja ispitanika ( $N=152)$, u istraživanju je sudjelovala $71(46,71 \%)$ žena i $81(53,29$ \%) muškarac. Kao profesor stručnog predmeta u nastavnom procesu sudjeluje 88 (57,89 \%) ispita- nika, 25 (16,45\%) ispitanika sudjeluje kao voditelj praktične nastave, a njih 39 (25,66 \%) ujedno obavlja poslove profesora stručnog predmeta i voditelja praktične nastave. Ispitanici sudjeluju u edukaciji učenika različitih strukovnih usmjerenja: strojarskih, elektrotehničkih, poljoprivrednih, ugostiteljskih i uslužnih djelatnosti. Najviše ispitanika ( $N=48,31,58 \%$ ) ima više od 20 godina radnog iskustva kao nastavnik (slika 2).

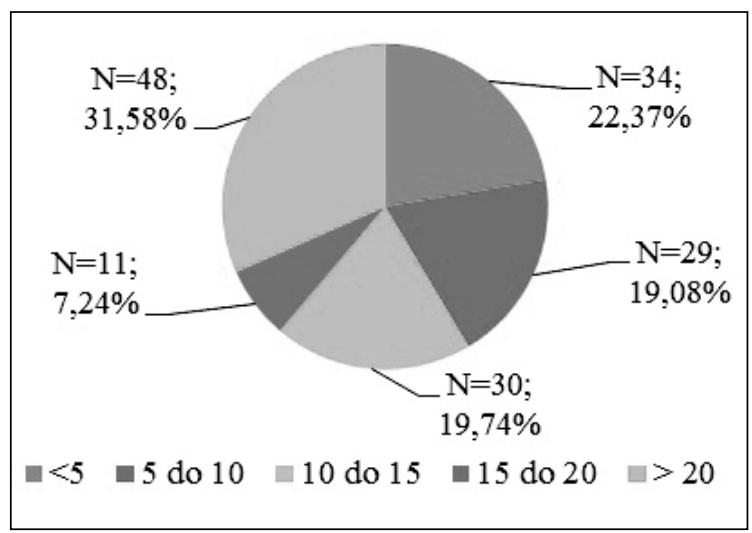

Slika 2. Godine radnog iskustva u obrazovnoj instituciji

Figure 2. Working experience in educational institution

Izvan obrazovnih institucija ranije je bilo zaposleno $93(61,18 \%)$ ispitanika te većinom imaju radno iskustvo u struci za koju sada educiraju učenike, dok 59 (38,82 \%) ispitanika navodi kako nema prethodno radno iskustvo izvan obrazovnih institucija. Znanja iz područja sigurnosti i zaštite zdravlja na radu $125(82,24 \%)$ ispitanika steklo je sudjelovanjem na tečajevima, seminarima i sličnim oblicima stručnog usavršavanja, a tijekom redovitog školovanja znanja o ovoj temi steklo je 99 $(65,13 \%)$ ispitanika (slika 3). Od ukupnog broja ispitanika ( $\mathrm{N}=152)$, razmjenom znanja i iskustava s kolegama, znanje iz zaštite na radu stekla su 92 $(60,53 \%)$ ispitanika, istraživanjem stručne literature $88(57,89 \%)$, a kroz radno iskustvo izvan obrazovne institucije $68(44,74 \%)$ ispitanika.

Za pripremu i provođenje nastave 137 $(90,13 \%)$ ispitanika koristi primjere iz prakse (slika 4.). Stručnu literaturu kao izvor za pripremu nastave navodi 125 (82,24\%) ispitanika, dok 122 $(80,26 \%)$ ispitanika ističe vlastito iskustvo. Škol- 
ske udžbenike u pripremi i provođenju nastave koristi 107 (70,39 \%) ispitanika. Brošure i slične materijale koristi 91 (69,87\%) ispitanik, materijale dostupne na internetskim stranicama 85 $(55,92 \%)$, a videomaterijale $83(54,61 \%)$ ispitanika. U pripremi i provođenju nastave goste-predavače koristi 12 (7,89\%) ispitanika.

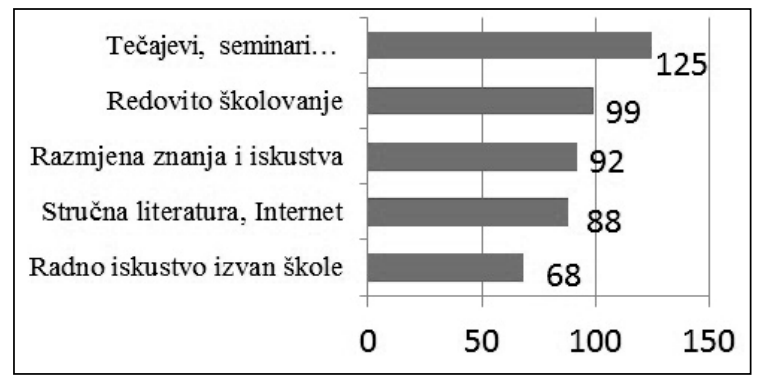

Slika 3. Stjecanje znanja iz zaštite na radu

Figure 3. Acquiring knowledge in occupational safety and health
U istraživanju $95(62,50 \%)$ ispitanika navodi kako učenike podučava o zaštiti na radu kontinuirano tijekom cjelokupnog obrazovanja. Većina ispitanika ( $\mathrm{N}=114,75,00 \%)$ slaže se ili se izrazito slaže s tvrdnjom kako je propisani sadržaj zaštite na radu dostatan za svladavanje osnovnih znanja iz zaštite na radu, njih 99 (65,13 \%) smatra da

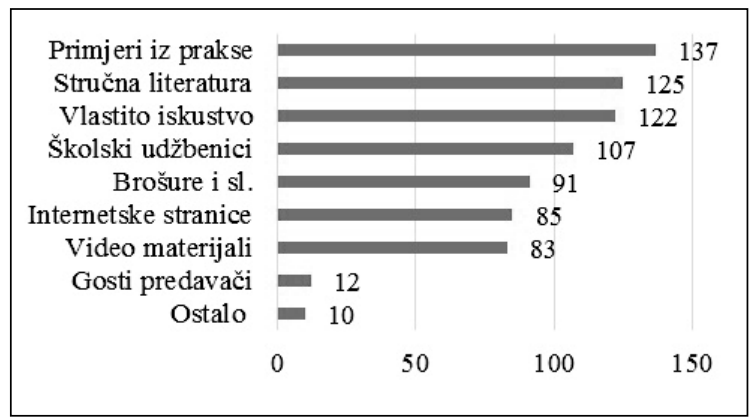

Slika 4. Učestalost korištenja materijala u pripremu i provođenje nastave

Figure 4. Frequency of materials used in preparation and cunducting classes

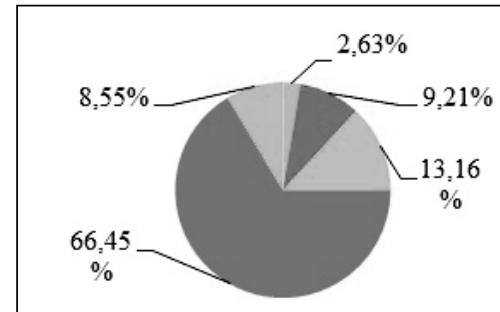

Propisani sadržaj zaštite na radu je dostatan za svladavanje osnovnih znanja iz ZNR

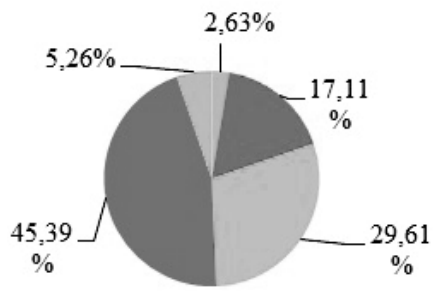

Učenici su zainteresirani za zaštitu na radu

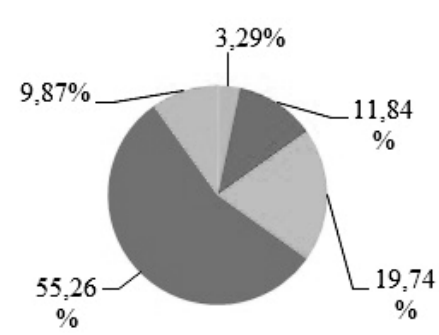

Propisani fond sati za zaštitu na radu je dostatan za svladavanje osnovnih znanja iz ZNR

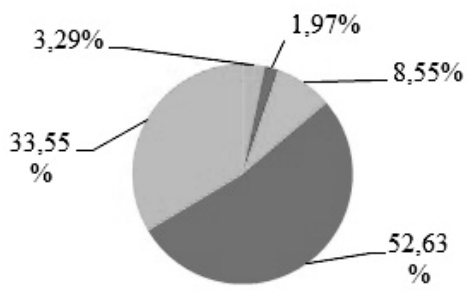

Škola prepoznaje važnost zaštite na radu

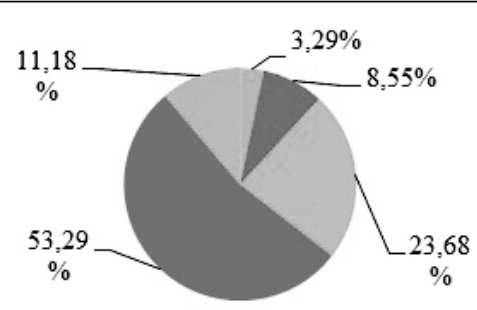

Dostupni materijali potrebni za provođenje nastave dostatni su za svladavanje osnovnih znanja iz ZNR

$$
\begin{aligned}
& \text { izrazito se ne slažem } \\
& \text { ne slažem se } \\
& \text { nisam siguran } \\
& \text { nslažem se } \\
& \text { izrazito se slažem }
\end{aligned}
$$

Slika 5. Vrednovanje dostatnosti propisanog sadržaja, fonda sati, dostupnih materijala za svladavanje osnovnih znanja iz zaštite na radu, zainteresiranost učenika za zaštitu na radu te prepoznavanja važnosti zaštite na radu od škole Figure 5. Evaluation of sufficiency of prescribed content, prescribed time, available materials for acquisition of basic knowledge in occupational safety and health, interest of students in occupational safety and health and recognition of importance of occupational safety and health by the school 
je za istu svrhu dostatan propisan fond sati za zaštitu na radu, a da su dostupni materijali za provođenje nastave također dostatni smatra 98 $(64,47 \%)$ ispitanika (slika 5). Zanimljiv je podatak kako podjednak broj ispitanika ima oprečna mišljenja oko zainteresiranosti učenika za zaštitu na radu. Od ukupnog broja ispitanika ( $\mathrm{N}=152)$, njih $77(50,66 \%)$ se slaže ili se izrazito slaže s tvrdnjom kako su učenici zainteresirani za zaštitu na radu, dok se 75 (48,68 \%) ispitanika ne može složiti s tom tvrdnjom ili nije sigurno. Iz potonjeg može se zaključiti kako je u provođenju nastave potrebno koristiti materijale koji će zainteresirati učenike za temu zaštite na radu, poput videomaterijala, primjera iz prakse i sl. Pozitivno je što 131
$(86,18 \%)$ ispitanik smatra kako škola u kojoj je zaposlen prepoznaje važnost zaštite na radu.

Ispitanici su pozitivno ocijenili korisnost svih ponuđenih izvora za svladavanje osnova zaštite na radu, a vrlo korisnim ocijenjeni su primjeri iz prakse od 97 (63,82\%) ispitanika te u jednakom broju ( $\mathrm{N}=72,47,37 \%)$ prethodno iskustvo nastavnika i stručna praksa (slika 6).

Tek manji broj ispitanika naveo je poteškoće s kojima se susreće prenoseći znanja iz područja zaštite na radu npr. nedostatak odgovarajućih materijala za provođenje nastave, općeniti školski udžbenici i ispiti za provjeru znanja iz zaštite na radu koji nisu usmjereni na pojedina strukovna

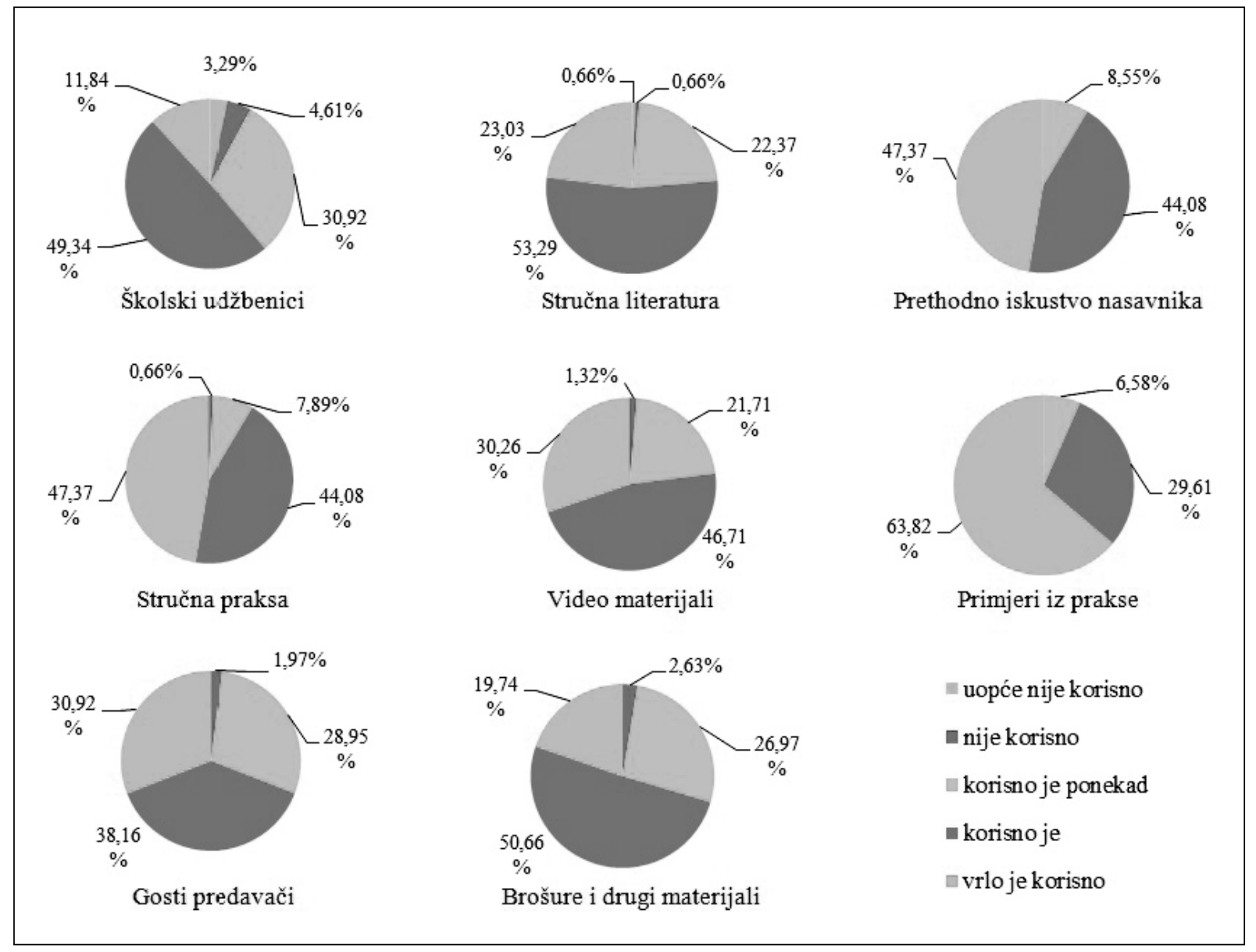

Slika 6. Vrednovanje izvora za svladavanje osnova zaštite na radu

Figure 6. Evaluation of sources used for mastering ocupational safety and health basics 
zanimanja, premalo dostupnog odgovarajućeg videomaterijala, nedostatna ili zastarjela sredstva i oprema za provođenje praktične nastave, nedostatak osobne zaštitne opreme. lako podjednak broj ispitanika ima podijeljena mišljenja oko zainteresiranosti učenika za zaštitu na radu, ipak se često navodi nedostatak svijesti o važnosti ove teme te uvriježeno mišljenje učenika kako zakonske odredbe u vezi sa zaštitom na radu neće biti primijenjene na radnom mjestu.

Ispitanici koji su dali svoje prijedloge za svladavanje poteškoća u edukaciji učenika, najčešće navode izradu nastavnih materijala usmjerenih na pojedina strukovna zanimanja, uključivanje u nastavu više videomaterijala, praktičnih primjera i gostujućih predavača. Dio ispitanika izrazilo je želju i potrebu za stručnim usavršavanjem iz zaštite na radu (npr. siguran rad s pesticidima), a navode i potrebu za pojačanim inspekcijskim nadzorima u školi i kod poslodavca. Ispitanicima je dana mogućnost da istaknu teme (pitanja) koje smatraju značajnim za unapređivanje ovog područja, a da nisu obuhvaćene konkretnim upitnikom. Iz pristiglih odgovora može se zaključiti kako ispitanici nisu istakli teme koje nisu obuhvaćene upitnikom.

\section{ZAKLJUČAK}

Strukovno obrazovanje ima za cilj omogućiti učenicima stjecanje temeljnih i strukovnih kompetencija potrebnih za tržište rada $^{2}$ što svakako podrazumijeva i znanje iz zaštite na radu. Cilj ovog istraživanja bio je utvrditi načine i metode podučavanja zaštite na radu, probleme s kojima se suočavaju nastavnici pri transferu znanja iz

Zakon o strukovnom obrazovanju, N.N., br. 30/09., 24/10., 22/13., 25/18 zaštite na radu u srednjim strukovnim školama te doznati njihove prijedloge za unapređivanje obrazovnog sustava. Nastavnici su istaknuli potrebu za izradom literature prilagođene učenicima i pojedinim zanimanjima, dodatnim stručnim usavršavanjem, videomaterijalima i sadržajima prilagođenim interesima učenika te pojačanim inspekcijskim nadzorima. Prije početka izvođenja praktičnog dijela kurikuluma učenici polažu ispit kojim potvrđuju da su usvojili sadržaje iz osnova zaštite na radu propisane strukovnim kurikulumom. ${ }^{3}$ Trenutna praksa je da nastavnici za provjeru znanja iz osnova zaštite na radu koriste općenite ispite različitih izdavača koje mnogi od njih smatraju neodgovarajućima. Istraživanje nije pokazalo zašto nastavnici sami ne izrade ispitne zadatke prilagođene stvarnim rizicima učenika koje educiraju. Nastavnike je potrebno poticati da za provjeru znanja koriste ispitna pitanja usmjerena na rizike pojedinih strukovnih zanimanja što će u konačnici pridonijeti kvalitetnijoj edukaciji iz zaštite na radu.

Nužno je razmotriti mogućnost korekcije kurikula koje će biti usklađene s potrebama tržišta rada i relevantnim nacionalnim strategijama razvoja gospodarstva. Nacionalni kurikulum za strukovno obrazovanje ${ }^{4}$ u svojim uvodnim odredbama poziva se na pružanje trajne potpore u profesionalnom razvoju nastavnicima, a sve u cilju obrazovanja visokokvalitetne radne snage.

Potrebno je poticati na izradu prikladne literature te organizaciju dodatnih edukacija profesora i voditelja praktične nastave iz zaštite na radu jer je njihov utjecaj na formiranje zdravih i sigurnih radnih navika kod učenika, budućih mladih radnika iznimno važno.

\footnotetext{
${ }^{3}$ Pravilnik o načinu organiziranja i izvođenju nastave u strukovnim školama, N.N., br.140/09.

${ }^{4}$ Odluku o donošenju nacionalnog kurikuluma za strukovno obrazovanje, N.N., br. 62/18.
} 


\section{LITERATURA}

Krišto, I., Batak, M., Paskaš Dlugoš, S.: Creating a safety culture - teaching and learning $\mathrm{OSH}$ in secondary vocational schools in Croatia, Book of Abstracts, 56, ICOH SCETOH Symposium, Zagreb, 26. - 28. 10. 2017.
Odluka o donošenju nacionalnog kurikuluma za strukovno obrazovanje, N.N., br. 62/18.

Zakon o strukovnom obrazovanju, N.N., br. 30/09., 24/10., 22/13., 25/18.

Pravilnik o načinu organiziranja $i$ izvođenju nastave u strukovnim školama, N.N., br.140/09.

\title{
RESULTS OF RESEARCH ON THE ATTITUDES AND NEEDS OF PROFESSORS OF VOCATIONAL SUBJECTS AND VOCATIONAL TRAINING TEACHERS IN SECONDARY VOCATIONAL SCHOOLS
}

\begin{abstract}
SUMMARY: The paper presents the results of the research undertaken to pinpoint the attitudes and needs of professors of vocational subjects and of vocational training teachers in secondary vocational schools with focus on occupational safety and health. The results of the research indicate a diversity of profiles (age, sex and work experience in teaching) of persons participating in the teaching process, and, especially, with regard to their work experience in the real economy sector. Furthermore, results illustrate the various difficulties encountered by teachers in their work as well as the necessity to take measures that would facilitate transfer of knowledge and stimulate development of positive attitudes on occupational safety and health among students.
\end{abstract}

Key words: professors of vocational subjects, vocational training teachers, vocational training, secondary vocational schools, occupational safety and health 